\title{
Roteirização para redução do custo de transportes: um estudo de caso em uma empresa de EPIs - Natal/RN
}

\author{
Caio Gabriel Alves Bezerra Correia de Lima - gabriel.caio.arkan@ gmail.com IFRN \\ Helckton Fernandes Pimentel - helcktonfernandes057@gmail.com IFRN \\ Monalisa Maria da Silva Furtado - monalisamaria_1@outlook.com IFRN \\ Valquíria Aparecida dos Santos - valquiriasantos2004@gmail.com IFRN \\ Carla Simone de Lima Teixeira Assunção - carla.teixeira@ifrn.edu.br - orientadora - UFRN
}

\section{Resumo}

A roteirização visa criar rotas otimizadas, isto é, as mais curtas distâncias possíveis entre quaisquer pontos, além de ter sua influência sobre a redução de custo e a otimização de recursos. Para esse fim, buscamos a melhor rota de entregas em uma empresa franquiada de EPIs afetando também na minimização dos gastos com o transporte, sendo eles, responsáveis por um dos principais custos dentro da logística. A má gestão desses e de outros custos são um dos motivos fundamentais para a queda de empresas desse porte, por esse motivo uma boa administração é indispensável para prevenir o mesmo, e melhorar a qualidade na prestação de serviço e a satisfação dos clientes.

Palavras-chave: Custos, Frete, Logística, Roteirização, Transporte.

\section{Introdução}

A rede de franquias está crescendo vertiginosamente e segundo o SEBRAE (2018), esse mercado deverá crescer ainda mais. Porém também aponta que $48 \%$ das empresas não conseguem sobreviver os primeiros três anos e um dos principais motivos é a má gestão dos custos.

Portanto, a gestão de custos em pequenas e médias empresas é de tal relevância que pode significar a sua sobrevivência no mercado, cabendo então ao gestor catalogar seus custos e saber onde reduzir e onde investir. Além disso, um dos maiores gastos em uma empresa é o transporte, e uma aliada para minimizá-los seria a roteirização, uma vez que, ao construir as melhores rotas, impõem aos veículos novos parâmetros otimizados de circulação. iTransport (2018).

Dito isso, este artigo propõe indicar soluções para reduzir os custos e aperfeiçoar as operações de transporte de uma empresa de venda de equipamentos de proteção individual e coletivo (EPIs e EPCs), através do mapeamento das rotas de entrega e correção dos possíveis problemas existentes, aumentando assim a eficiência e nível de serviço ofertado ao cliente. 
A empresa escolhida é uma franquia a qual tem várias filiais no país e larga experiência no mercado de EPIs. A filial de Natal não possui frota própria e todas as entregas são feitas com veículos terceirizados, onde os custos do aluguel são previamente acertados com a transportadora de acordo com o destino de entrega. $\mathrm{O}$ proprietário informou que a prestadora do serviço de transporte atende satisfatoriamente o que é solicitado, disponibilizando, inclusive, um veículo extra caso ocorra algum problema com o veículo em trânsito.

\section{Fundamentação Teórica}

\subsection{Logística}

Logística é a gestão cujas atividades estão voltadas para o planejamento da armazenagem, circulação e distribuição de produtos. (Bock et al 2015).

Segundo Novaes (2007), é a logística que permite a concretização das metas definidas pela empresa. A logística é responsável pelo planejamento, implementação, controle e fluxo de bens, serviços e informações dentro da cadeia de suprimentos, o que a torna responsável pela forma como o produto chegará ao cliente.

Já Abarche et al (2011) relembra que a logística já foi dada como a culpada de entregas não feitas ou atrasadas, e hoje em dia envolve, além do transporte, a gestão do planejamento, controle do fluxo e armazenamento dos produtos e seus serviços associados (demanda de clientes, atendimento de pedidos, rastreamentos de entregas, e pagamentos atribuídos a logística), mesmo que executada por profissionais de outras áreas.

Daganzo (1996) caracteriza a logística como a administração da movimentação de materiais desde o seu ponto de origem ao seu ponto final, levando em consideração os limites de tempo e capacidade. Similarmente, Takac (2014) aponta que a gestão de transportes é um ramo da logística que envolve transportar a maior quantidade de mercadorias, com o mínimo custo e menor tempo possível.

Segundo Bowersox e Closs (2001) os cinco tipos de modais de transportes básicos são o rodoviário, o ferroviário, o aquaviário, o dutoviário e o aéreo. Sendo que a escolha do tipo de modal depende das características do produto, disponibilidade do e frequência do transporte, confiabilidade e custo.

O transporte rodoviário, modal abordado neste trabalho, possui vantagem diante dos demais modais, pois tem maior facilidade na realização do serviço porta-a-porta, devido à ampla malha rodoviária existente e as limitações de instalações dos demais meios.

Ballou apud Leite et al (2017) fala que algumas das atividades da logística são consideradas primárias porque ou elas contribuem com a maior parcela do custo total ou elas são essenciais para a coordenação e o cumprimento da tarefa Logística. E a área que absorve quase dois terços dos custos logísticos é a de transporte.

O processo de integração das informações entre os setores de transporte, estoque, armazenamento e movimentação tem sido 
considerado um fator estratégico importante na promoção de resultados positivos para a empresa, já que a competência logística é alcançada por meio de um alto nível de gerenciamento (VARGAS, 2005, p.22).

Dado isso, o gerenciamento do transporte dentro de uma empresa torna-se fundamental, pois gera grande impacto nos custos logísticos e totais da organização, sendo um fator determinante no quesito competitividade.

\subsection{Custos x Despesas}

Pompermaye et al (2002) dissertam sobre a importância de uma boa gestão de custos como um dos focos da estratégia, e favorece a permanência e conquista de mercado:

"O perfil dos mercados de bens e serviços mostra que as empresas bem preparadas são sempre vitoriosas: os bens dos incompetentes são transferidos para o patrimônio dos competentes."

Fundamenta também sobre as atividades geradoras de recursos - geradas pela venda de bens/serviços - denominadas atividades 'fim', E as demais como atividade 'meio'. Os gastos com atividades 'fim' chamadas 'custos' e as atividades 'meio' nomeadas 'despesas'.

Já Dultra apud Carareto et al (2006) define custos como 'custos realizados' e despesas como 'custos a realizar', onde os custos realizados são os consumidos para efeito de resultado contábil do período. Ex.: mão-de-obra, matérias-primas, depreciações, que integram o custo do produto vendido. Quanto aos custos a realizar, formam as contas patrimoniais referem-se aos produtos que já foram fabricados, no entanto, continuarão classificados como custos a realizar até que estes produtos sejam comercializados, passando então para custos de produtos vendidos.

Desenvolvendo mais o assunto, Viceconte et al (2011) classifica os custos em fixos (aluguel e depreciação de equipamentos), variáveis (matéria prima utilizada ou horas extra na produção), semivariáveis (custos que variam de acordo com a produção: energia elétrica) e por fim semifixos (custos fixos em uma faixa de produção). Bem como as despesas, sendo as variáveis as que têm seu valor em função das vendas comissões aos vendedores - e as fixas aquelas que são pagas independentes da empresa.

\subsection{Custos de Transporte}

As atividades de qualquer organização são geralmente divididas entre custos fixos e variáveis, para Wanke (2010) a agrupação de diferentes itens de custo, visa primeiramente apoiar decisões na empresa e determinar o valor do objeto de custo.

Crepaldi (2010) define os custos fixos como aqueles cujo total não varia de acordo com o volume produzido. É um custo fixo no total, mas variável nas unidades produzidas - quanto mais produzir, menor será o custo por unidade. 
Já Lima (2001) cita os principais custos de transportes em custos fixos que apresenta a seguinte definição:

- Depreciação: representa a perda de valor do bem;

- Remuneração de Capital: é o ganho obtido no mercado financeiro ao investir valor do veículo;

- Pessoal (motorista): são os salários e encargos sociais atribuídos aos motoristas e ajudantes que trabalham diretamente no transporte;

- Custos administrativos: são os custos indiretos em relação ao veículo (Funcionários que trabalham com empilhadeiras, nas vendas, etc.);

- Seguro do Veículo: é um custo pago à seguradora no caso de haver sinistro (quebra ou acidente), pode ser ressarcido;

- IPVA/licenciamento do DETRAN: é o gasto anual em tributos e licenças para o veículo transitar pelo país.

Já os custos variáveis são os que variam proporcionalmente ao volume produzido. (CREPALDI 2010)

Lima (2001) menciona que os custos que dependem da quilometragem usada pelo veículo e descreve estes custos como:

- Pneu: gasto na compra de pneus novos em substituição aos velhos, recapagem;

- Combustível: custo com o uso do veículo nas rotas de entregas;

- Lubrificante: gasto com lubrificantes para facilitar a transmissão interna e o sistema do motor;

- Lavagem: custo para lavagem interna e externa do veículo;

- Manutenção: gasto com peças de reposição do veículo, troca de peças defeituosa, é necessário ser rateado por quilometro rodado;

Wanke apud Wanke (2010) acrescenta outros como: capacidade alocada aos clientes; facilidade de manuseio do produto; facilidade de acomodação; risco ligado ao carregamento; sazonalidade; tempo de carregamento e descarga; e existência de carga de retorno. Menciona também que um dos fatores mais importantes na elaboração das estratégias nas empresas que prestam serviço de transporte, é a decisões relacionadas ao transporte, pois afetam consideravelmente a interação entre os custos fixos e variáveis.

Sobre a associação Wanke (2010), discorre:

"Na decisão entre integração vertical e terceirização, a escolha está a favor da operação de uma frota própria com a capacidade dimensionada pelo pico da demanda levaria a uma proporção maior de custos fixos no transporte. Por outro lado, a operação de frota própria com capacidade estimada pela média associada à contratação de prestadores de serviços, poderia levar a uma proporção maior de custos variáveis." 


\subsection{Roteirização}

A roteirização é, em suma, uma necessidade para os veículos da sua frota para que eles realizem determinado serviço de distribuição de produtos ou serviço, frequentemente relaciona-se roteirização com um problema de distribuição física.

Um problema real de roteirização é definido por três fatores fundamentais: decisões, objetivos e restrições (Novaes apud Partyka e Hall, 2000). A decisão diz respeito à localização de seu grupo de clientes, que devem ser visitados, um conjunto de veículos e seus funcionários, a programação e a sequência.

Como diz Novae (2015) "Como objetivos principais, o processo de roteirização via propiciar um serviço de alto nível aos clientes, mas, ao mesmo tempo mantendo os custos operacionais de capitais tão baixos quanto possível.".

Levando em consideração que se deve obedecer a certas restrições, tais como: passar por todos os clientes usando os recursos disponíveis; respeitar a jornada de trabalho dos funcionários; e, respeitar as restrições de trânsito, tais quais, velocidade, horário de carga e descarga, tamanho máximo do veículo, dentre outros. Um método muito utilizado na resolução de problemas isolados, utilizando roteirização com restrições, é o método de Clarke e Wright, esse método foca em minimizar o tempo, à distância e os veículos utilizados, reduzindo os custos de operação.

Problema do Caixeiro Viajante - PCV, o PCV se resume em visitar determinado número de cidades em uma região, determinando a sequência que minimize o percurso total. Existem métodos para resolver um PCV, são eles: método de construção de roteiro; métodos de melhoria do roteiro; método de inserção do ponto mais distante. Explanaremos melhor a seguir.

\subsubsection{Método de construção de roteiro}

Neste método se deve ir ligando cada ponto ao seu vizinho mais próximo, tomando cuidado para não inserir aqueles que já foram visitados, não é um dos métodos mais eficazes, mas é rápido e simples, além de fornecer uma solução inicial que pode ser melhorada depois.

\subsubsection{Método de melhoria de roteiro}

Os dois métodos de melhoria mais utilizados são o 2-opt e o 3-opt. (Sizlo 2006). O método 2-opt, o mais simples, se dá depois de criar um roteiro inicial qualquer, remover 2 arcos e tentando reconectar os nós que formam esses arcos, alterando as ligações, se produzir um resultado melhor, substitui, caso não, retorna ao roteiro anterior e tenta com outros dois arcos. O processo só termina quando não existir mais possibilidade de melhoria ao se fazer todas as trocas possíveis. Já o método 3-opt é semelhante com o 2-opt, com a diferença de que as alterações são com três pares de arcos de cada vez. Outra diferença importante em relação ao método anterior é que agora são possíveis sete alterações diferentes para cada configuração básica. (Syslo 2006). 


\subsubsection{Método de inserção do ponto mais distante}

Neste método se deve verificar qual o ponto mais distante e liga-lo ao inicial, formando um roteiro, após isso se deve procurar o mais distante dele, e formar arcos, sem cruzá-los e sim os abrindo como um desenho de ligação de pontos, e seguir assim por diante até estar com o roteiro completo.

\section{Metodologia}

A abordagem usada nesta pesquisa foi à exploratória para com esse estudo de caso, encontrar a melhor roteirização aos veículos utilizados nas entregas dos produtos que a empresa vende aos seus clientes. A empresa não tem uma padronização nas entregas, pois a incumbência é de veículos terceirizados que executam tais entregas de acordo à demanda da empresa. Sem qualquer critério técnico, a qual pode ocasionar em alto custo nas despesas de transporte dos produtos, destacando que os custos com transportes chegam a compor até $60 \%$ dos custos logísticos de uma organização. Portopédia (2016).

Os dados obtidos foram na forma de um questionário a qual o proprietário da empresa franquiada nos respondeu, também alegando a vantagem competitiva em terceirizar as entregas. A metodologia nesse estudo foi direcionada para solucionar o problema de roteirização através de conhecimento geográfico e de ferramentas de análise de diferentes rotas para minimizar tempo de percurso, volume da carga e gastos com combustível.

\section{Caracterização da empresa}

O site da companhia a apresenta como fornecedora de equipamentos de Proteção Individual e Coletiva focada em atender as necessidades específicas do cliente. Nossa experiência como usuários destes produtos, aliada à presença permanente de um Técnico em Segurança do Trabalho com vivência de campo em várias áreas, nos possibilita entender suas necessidades, sugerindo e otimizando a utilização dos equipamentos adequados a cada tipo de trabalho.

A empresa onde o estudo foi realizado, é a filial de Natal/RN, faz parte da maior rede de franquias de equipamentos de segurança, e que segue os mesmos preceitos da missão apresentada no portfólio da empresa matriz. Inaugurada em julho de 2019, na Av. Bernardo Vieira, mesmo com pouco tempo na praça, conta com uma carteira de clientes fiéis. Nesse contexto e com pouca concorrência, proporciona um faturamento razoável, dando assim um ponto de equilíbrio dos seus negócios antes do terceiro mês.

Os produtos negociados vão desde óculos, protetores auditivos, macacões, capacetes, sinalizadores, calçados, etc. até luvas de todos os modelos e tipos. No 
momento conta com dois funcionários, o gerente na loja e um motorista que é responsável pelo frete.

\section{Resultados e Discussão}

Após visitas na empresa, foi constatado através da entrevista que a filial de Natal da companhia tem o mínimo de controle de custos com o frete das suas mercadorias para seus clientes. Diante disso, foi deduzido que tanto este controle quanto a roteirização dos fretes são empíricos, pois semanalmente é destinando uma quantia de dinheiro para colocar combustível no veículo que faz a entrega e sem nenhum monitoramento de roteirização, estabelecendo o caminho mais curto que atenda seus clientes. Além disso, o veículo, que é terceirizado, não possui sistema de rastreio, confiando ao motorista o compromisso que ele vá direto ao cliente e retorne ao ponto inicial sem alterar o caminho.

Foi solicitado, então o endereço dos três principais clientes com o propósito de sugerir um trajeto com a menor distância percorrida entre eles. Com o diagnóstico apurado a sugestão de propor melhorias na minimização dos custos de transporte e, utilizando os conceitos aprendidos na disciplina de Pesquisa Operacional, adotamos o método do "Vizinho mais próximo" aliado à "Heurística da Inversão" para encontrar o melhor caminho para atender os três clientes.

Enquanto o primeiro método diz que a partir de um ponto inicial, os nós devem se conectar ao vizinho mais próximo até que todos os pontos sejam atendidos sem formar um sub circuito, o segundo sugere uma inversão de pontos vizinhos para que haja uma melhora na solução encontrada com o método anterior.

Imagem 1 - Grafo de representação geográfica entre a empresa e seus clientes.

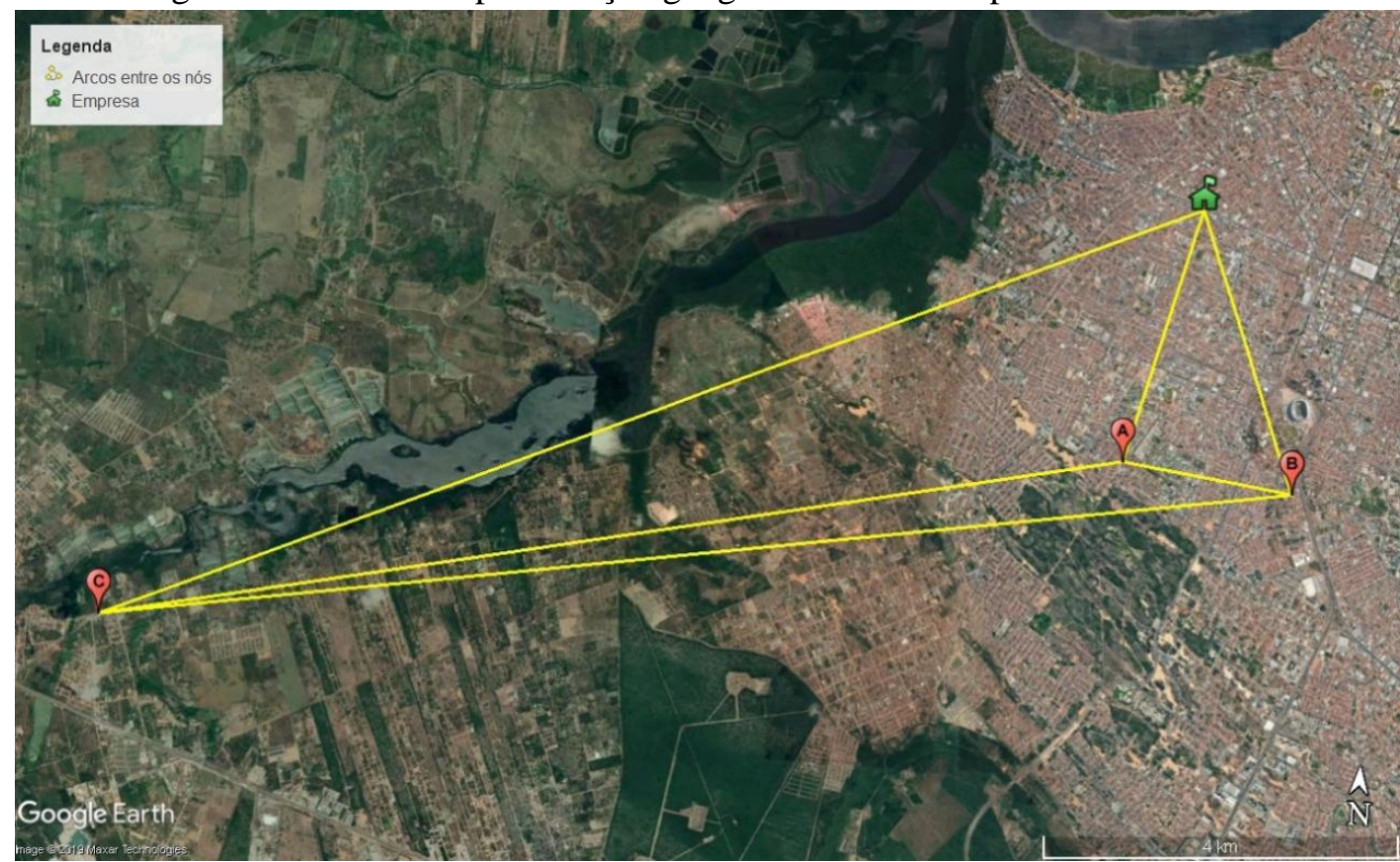

Fonte: Google Earth. 
$\mathrm{Na}$ imagem anterior, é visto os arcos desenhados entre a empresa e seus clientes em linha reta apenas para representação gráfica. É importante ressaltar que, as distâncias exibidas na tabela a seguir, foram obtidas através do Google Maps considerando as leis de trânsito da cidade.

Tabela 1 - Distância em km entre os nós

\begin{tabular}{c|c|c|c|c} 
& EMPRESA & A & B & C \\
\hline EMPRESA & - & 3,6 & 4,9 & 16,3 \\
\hline $\mathrm{A}$ & 4,0 & - & 3,0 & 15,5 \\
\hline $\mathrm{B}$ & 5,4 & 2,9 & - & 18,3 \\
\hline $\mathrm{C}$ & 15,9 & 14,8 & 17,9 & - \\
& \multicolumn{3}{c}{ Fonte: Autores. }
\end{tabular}

Como a roteirização é feita de maneira empírica, o primeiro ponto visitado é o cliente A, pois é o mais próximo do ponto inicial. Após isso, o veículo se dirige ao cliente B e para atender C, que se localiza em Macaíba. O Google Maps sugere que a ligação B-C seja realizada via BR-101/304 (Parnamirim), totalizando 43,6 km.

Imagem 2 - Situação 1: Trajeto realizado atualmente para a situação estudada

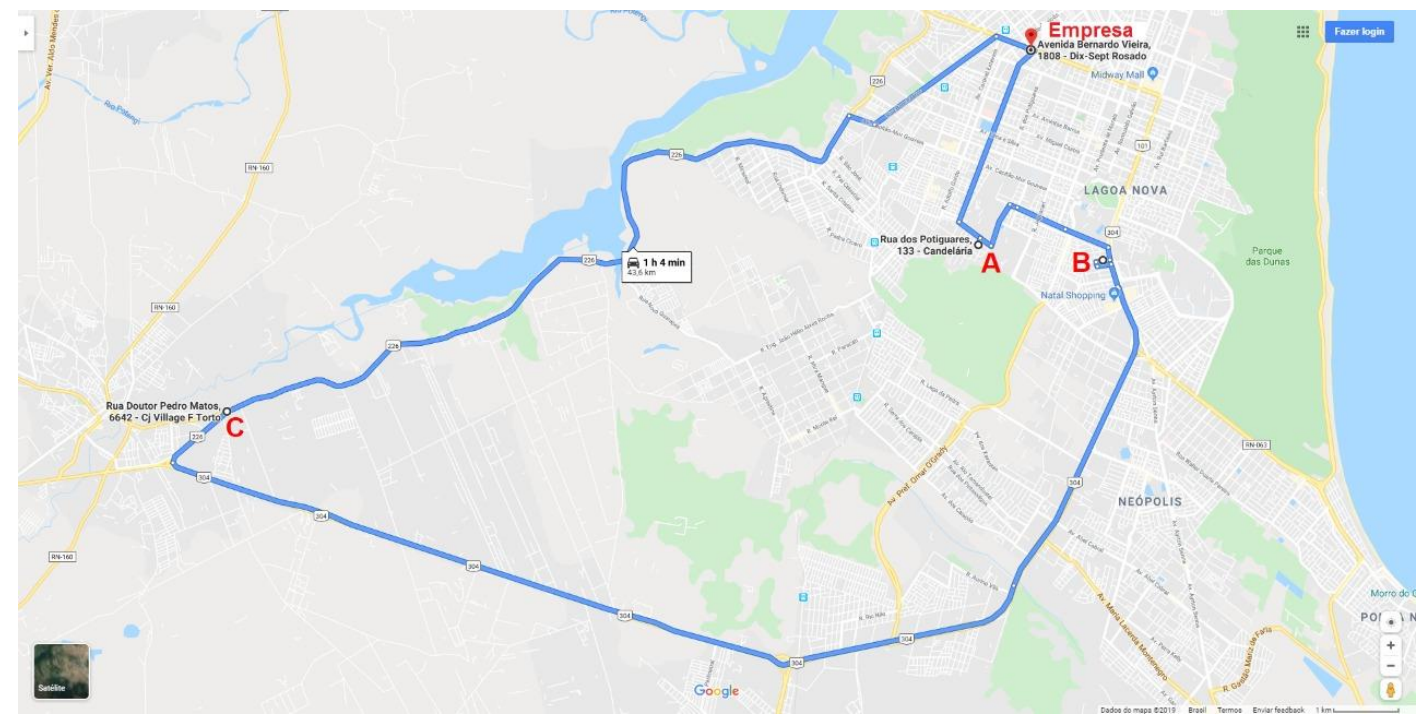

Fonte: Google Maps

Partindo da empresa, o método vizinho mais próximo indica que o caminho a ser percorrido é passando pelos pontos "Empresa - A - B - C - Empresa", dando um total de 40,4 km, conforme ilustra imagem a seguir: 
Imagem 3 - Situação 2: Trajeto feito pelo método "vizinho mais próximo"

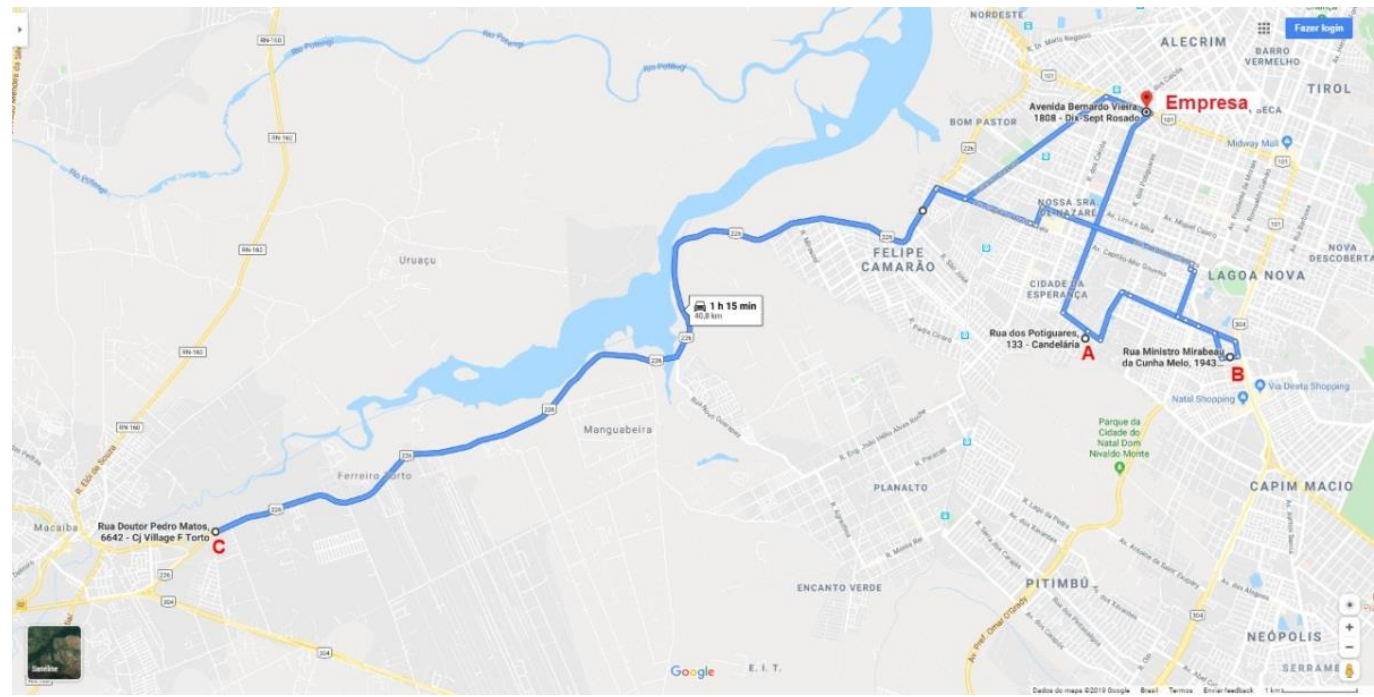

Fonte: Google Maps

Entretanto, se usarmos a heurística da inversão e trocarmos os pontos "A" e "B", conseguimos o trajeto "Empresa - B - A - C - Empresa", com um total de 39,3 km.

Imagem 4 - Situação 3: Trajeto alterado pela "Heurística da inversão"

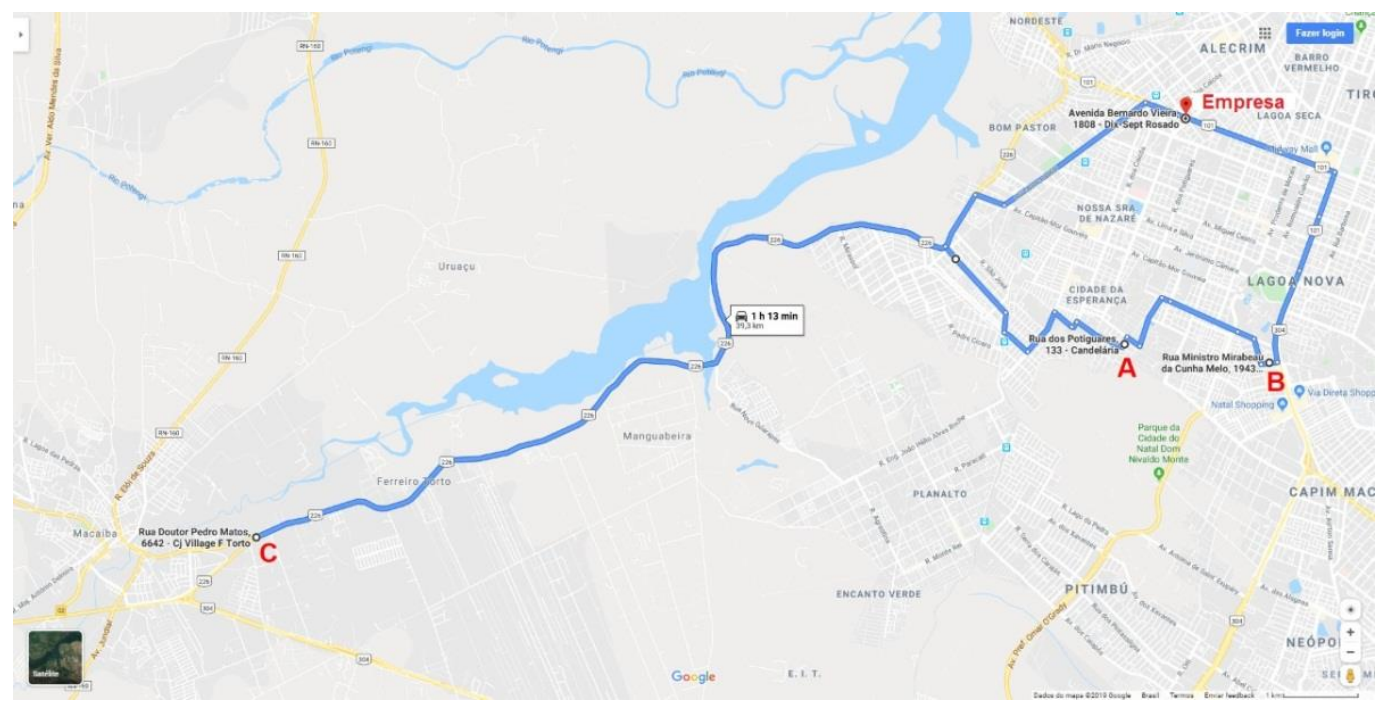

Fonte: Google Maps

Na comparação entre os métodos expostos anteriormente, foi percebido que este último é o que traz maior vantagem em redução de custos de combustível para a empresa. Considerando o preço da gasolina em $\mathrm{R} \$ 4,66$, temos o seguinte cenário descrito na tabela 2: 
Tabela 2 - Comparação de valor pago de

\begin{tabular}{c|c|c} 
Situação & Distância $(\mathrm{km})$ & Valor pago $(\mathrm{R} \$)$ \\
\hline 1 & 43,6 & 20,32 \\
\hline 2 & 40,8 & 19,01 \\
\hline 3 & 39,3 & 18,31 \\
& Fonte: Autores.
\end{tabular}

Equipamentos de proteção individual e coletiva por finalidade precisam ser de fácil manuseio então não apresentam dificuldades em seu acondicionamento. Por serem "encaixáveis" (no caso de cones de sinalização, por exemplo), "dobráveis" (coletes de sinalização) ou apresentarem pouco volume (placas de "Perigo! Inflamável" ou "Saída de Emergência"), a maioria deles não apresentam um volume ou densidade representativa, mesmo que comprados em grandes quantidades e podem ser facilmente transportados em caixas ou sacolas plásticas.

A empresa em questão, por ser uma franquia, precifica os seus produtos de acordo com tabela elaborada pela matriz, mas de acordo com o representante, permite aos seus franquiados dar descontos de acordo com a quantidade de produtos adquiridos pelo cliente ou fazer promoções. Além disso, a empresa realiza entregas grátis para compras acima de $\mathrm{R} \$ 100,00$.

Tabela 2 - Comparativos de preços entre a empresa em questão e as concorrentes

\begin{tabular}{l|rr|rr|rr}
\multicolumn{1}{c|}{ Produtos } & \multicolumn{2}{c|}{ Empresa X } & \multicolumn{2}{c|}{ Empresa A } & \multicolumn{2}{c}{ Empresa B } \\
\hline Óculos Sky Fume & $\mathrm{R} \$$ & 2,45 & $\mathrm{R} \$$ & 2,34 & $\mathrm{R} \$$ & 3,00 \\
\hline $\begin{array}{l}\text { Bota EL. Bidens BIQ. } \\
\text { PVC }\end{array}$ & $\mathrm{R} \$$ & 33,35 & $\mathrm{R} \$$ & 49,00 & $\mathrm{R} \$$ & 39,00 \\
\hline $\begin{array}{l}\text { Luva Raspa Punho 7 } \\
\text { cm }\end{array}$ & $\mathrm{R} \$$ & 6,80 & $\mathrm{R} \$$ & 7,90 & $\mathrm{R} \$$ & 6,00 \\
\hline Capacete - A.T. & $\mathrm{R} \$$ & $\begin{array}{c}17,05 \\
\text { Fonte: Autores. }\end{array}$ & $\mathrm{R} \$$ & 15,27 & $\mathrm{R} \$$ & 19,50
\end{tabular}

Acima, na tabela 2, estão alguns dos produtos que são mais vendidos pela empresa e foi observado que existe um equilíbrio de preços na maioria deles, exceto a bota de segurança que está com um preço abaixo do mercado.

Também foi observado que os principais custos foram de energia elétrica, água e saneamento, funcionários, telefone fixo internet; enquanto as despesas foram de aluguel do prédio, do veículo, combustível, frete e publicidade. 


\section{Conclusão}

O presente trabalho referiu-se ao estudo de caso de uma empresa franquiada numa abordagem de melhoria nas entregas de suas mercadorias aos clientes. É possível perceber que pelo significativo grau de empirismo, a empresa precisa adotar uma postura de controle maior sobre os custos e despesas.

A utilização de softwares, como os de monitoramento via GPS para o veículo que realiza as entregas, de roteirização para escolher o melhor caminho para chegar ao endereço desejado e de controle de gastos (fixos e variáveis) é de grande valia, pois através de um investimento desse porte a empresa pode ter um retorno financeiro positivo e a partir daí, aumentar seu nível de serviço, oferecendo uma experiência ainda melhor para os seus clientes.

Através de uma simples troca na ordem de entrega nos endereços na roteirização avaliada (considerando a entrega de produtos para três clientes ao mesmo tempo), conseguiu-se uma economia de $\mathrm{R} \$ 20,03$ de combustível que seria equivalente a percorrer $4,3 \mathrm{~km}$ rodados por mês, e ao expandir isso para toda sua cartela de clientes, em entregas combinadas, a economia será ainda maior.

\section{Referências}

ABACHE; SANTOS; MONTENEGRO; SALLES; Gestão de Logística, Distribuição e Trade Marketing. $4^{\mathrm{a}}$ ed. Rio de Janeiro: Editora FGV, 2011. Disponível em: <encurtador.com.br/tTV26>. Acessado em: 25 de Nov. 2019.

BOWERSOX, D. J.; CLOSS, D. J. Logística Empresarial - O Processo de Integração da Cadeia de Suprimento. São Paulo: Atlas, 2007.

\section{BOGLOGISTICA; Como Elaborar Boas Rotas De Entrega E Reduzir Custos}

Logísticos? Jul. 2018. Disponível em:

$<$ https://www.bloglogistica.com.br/gestao/como-elaborar-boas-rotas-de-entrega-ereduzir-custos-logisticos/>. Acessado em: 18 de nov. 2019.

CARARETO; JAYME; TAVARES; VALE; Gestão Estratégica de Custos: custos na tomada de decisão. Revista de Economia da UEG, Anápolis (GO), Vol. 2, $\mathrm{n}^{\mathrm{o}} 2$, JUL/DEZ-2006. Disponível em: <encurtador.com.br/nrzBW >. Acessado em: 23 de Nov. 2019.

CACCALANO; CUNHA; Roteirização de veículos para o abastecimento de linhas de produção. Gest. Prod. vol.22 no. 4 São Carlos out. / dez. 2015. Epub 24-Nov-2015. Disponível em: http://dx.doi.org/10.1590/0104-530X1294-15 Acessado em: 15 de nov. 2019.

COBLI; O que é roteirização? Disponível em: <https://www.cobli.co/blog/o-que-eroteirizacao/>. Acessado em: 16 de nov. 2019. 
CUNHA; BOCK; QUADROS JÚNIOR, O Papel Da Logística Na Indústria Moveleira. Revista Maiêutica, Indaial, v. 3, n. 1, p. 13-18, 2015. Disponível em: <https://publicacao.uniasselvi.com.br/index.php/EMD_EaD/article/viewFile/1373/522>. Acessado: 25 de Nov. 2019.

CREPAUDI, Silvio Aparecido. Curso básico de contabilidade de custos. $5^{\text {a }}$ Ed. São Paulo: Atlas, 2010.

DAGANZO, C. F. Logistics systems analysis. $2^{a}$ Edição, Editora Springer, 1996.

EPI's Online. Disponível em: < https://www.episonline.com.br/>. Acessado em: 23 de Nov 2019.

ENOMOTO; LIMA; Análise da distribuição física e roteirização em um atacadista. Produção, v. 17, n. 1, p. 094-108, Jan. / Abr. 2007. Disponível em:< http://www.scielo.br/pdf/\%0D/prod/v17n1/06.pdf >. Acessado em: 16 de nov. 2019

Google Maps. Disponível em: <https://www.google.com/maps>. Acessado em 21 de Nov 2019.

GUIMARÃES; SCARPIN; STEINER; Políticas de distribuição com lote econômico de entrega em problemas de roteirização com estoque gerenciado pelo fornecedor $\mathrm{e}$ sistema logístico em três níveis. Gest. Prod. vol.22 no.1 São Carlos Jan. / Mar. 2015. Disponível em: <http://dx.doi.org/10.1590/0104-530X1044/13>. Acessado em: 18 de nov. 2019.

ILOS; Custos Logísticos. Disponível em: < https://www.ilos.com.br/web/tag/custoslogisticos/>. Acessado em: 15 de nov. 2019.

itransport. Disponível em: <https://www.itransport.com.br/>. Acessado em: 25/11/2019.

LEITE; SOUZA; SILVA; PORTUGAL JUNIOR; OLIVEIRA. A Logística e a Gestão da Cadeia de Suprimentos: Um Estudo em uma Empresa da Região Sul de Minas Gerais. Revista da Universidade Vale do Rio Verde, Três Corações, v. 15, n. 1, p. 676688, jan. / jul. 2017. Disponível em: <http://periodicos.unincor.br/index.php/revistaunincor/article/view/4046/3014>. Acessado em: 25 de Nov. 2019.

Loja do Mecânico. Disponível em: <https://www.lojadomecanico.com.br>. Acessado em: 23/11/2019.

NOVAES, A. G. Logística e gerenciamento da cadeira de distribuição. $4^{\mathrm{a}}$ ed. Rio de Janeiro: Elservier, 2015.

NOVAES, A. G. Logística e gerenciamento da cadeia de distribuição: estratégia, operação e avaliação. 3 ed. Rio de Janeiro: Elsevier, 2007.

SEBRAE. Disponivel em: 〈https://www.sebrae.com.br>. Acessado em: 21 de Nov 2019. 
POMPERMAYER; LIMA; Gestão de Custos. Disponível em: <encurtador.com.br/bopv2>. Acessado em: 23 de Nov 2019.

Portopedia. Disponível em: <https://portogente.com.br/portopedia>. Acessado em: 24 de Nov 2019.

TACKAC; SILVA; MARTINS; Logística de Serviços: Aplicação do Ciclo PDCA no Transporte Coletivo Urbano. Maiêutica - Cursos de Gestão. 2014. Disponível em: <https://publicacao.uniasselvi.com.br/index.php/GESTAO_EaD/article/view/1255/414> Acessado em: 25 de Nov 2019.

VARGAS, R. Análise dos custos de transporte de produtos da distribuidora Polina e cia Itda para atender os clientes da cidade de Guaíra. 2005. Monografia (Curso de Administração com Habilitação em Logística e Transportes) - Faculdade Assis Gurgacz. Cascavel.

VICECONTE; NEVES; Contabilidade de custos. $11^{\mathrm{a}}$ ed. rev. e atual. - São Paulo: Saraiva, 2013.

WANKE, Peter F. Logística e transporte de cargas no Brasil: produtividade e eficiência no século XXI. São Paulo: Atlas, 2010. Coleção Coppead de Administraçã 